\title{
Analytic Hierarchy Process-Based Environmental Criteria Weight Assessment and Prioritization for Suitable Petroleum Refining Plant siting in Edo State, Nigeria
}

\section{Aweh D.S. ${ }^{1}$ \\ Igbokwe J. I. ${ }^{2}$ \\ Ejikeme, J.O. ${ }^{3}$}

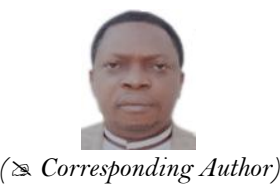

'Department of Surveying and Geoinformatics, Nnamdi Azikiwe University, Awka, Nigeria \& Department of Surveying and Geoinformatics, Auchi Polytechnic, Auchi, Nigeria.

Email:dsarveh2000@yahoo.com Tel: +284-8035867951

${ }_{2,3}$ Department of Surveying and Geoinformatics, Nnamdi Azikiwe University, Awka, Nigeria.

\section{Abstract}

In this paper, Saaty's Analytical Hierarchy Process (AHP) of Multi-Criteria Evaluation (MCE) technique was used to estimate the weights of some selected environmental criteria in the suitable siting of a Petroleum refining Plant. In doing this, fifteen (15) key environmental criteria, based on reviewed literature, specifications, and Environmental Impact Assessment Act (EIA) on the siting of petroleum refining plants were selected for this study, which includes Ground Water level, Proximity to major settlement, Proximity to Water bodies, Proximity to the Electricity transmission line, Land use / Land cover, Topography, Sensitive and Protected Areas proximity, Critically Polluted Areas (refuse dumpsites, landfill sites, etc.), Proximity to Existing Industrial areas, Major Transportation network, Flood zones, Proximity to crude oil supply (oil well), Wind speed, Large-scale Mines and Population density. The result from the calculated environmental criteria weights show proximities of Petroleum refinery to existing industrial areas; source of crude oil and Landuse/Landcover to have the highest influence value, followed by proximity to Water Body; Population Density; Groundwater Level; Major Settlement; Wind Speed; Transportation Network, Topography, while Sensitive/Protected Areas, Critically Polluted areas and Flood zones with the least influence value. The result of this AHP - based weight assessment will be used generally by Planners, Investors, Environmental Managers, and Oil and Gas experts as a general guide in the prioritization of criteria weights based on the influence of one criterion over the other in the suitability siting of petroleum refining plant.

Keywords: Criteria weight, Site selection, AHP-BASED MCE, Petroleum refinery, Edo State.

Citation | Aweh D.S., Igbokwe J. I., Ejikeme, J.O. (2021). Analytic Hierarchy Process-Based Environmental Criteria Weight Assessment and Prioritization for Suitable Petroleum Refining Plant siting in Edo State, Nigeria. Asian Review of Environmental and Earth Sciences, 8(1): 10-17.

History:

History:

Revised: 26 February 2021

Accepted: 18 March 2021

Published: 20 April 2021

Licensed: This work is licensed under a Creative Commons

Attribution 3.0 License (cc) Er

Publisher: Asian Online Journal Publishing Group
Acknowledgement: All authors contributed to the conception and design of the study.

Funding: This study received no specific financial support.

Competing Interests: The authors declare that they have no conflict of interests.

Transparency: The authors confirm that the manuscript is an honest, Transparency: The authors confirm that the manuscript is an honest,
accurate, and transparent account of the study was reported; that no vital accurate, and transparent account of the study was reported; that no vital
features of the study have been omitted; and that any discrepancies from the features of the study have been omitted;
study as planned have been explained.

Ethical: This study follows all ethical practices during writing.

\section{Contents}

1. Introduction

2. Materials and Methods 


\section{Contribution of this paper to the literature}

In this paper, Saaty's Analytical Hierarchy Process (AHP) of Multi-Criteria Evaluation (MCE) technique was used to estimate the weights of some selected environmental criteria in the suitable siting of a Petroleum refining Plant.

\section{Introduction}

The petroleum industry provides most of the needed fuel for everyday use for industrial, commercial, and domestic purposes. In fact, modern industrial civilization depends on petroleum and its products; the physical structure and way of life of the suburban communities that surround the great cities are the result of an ample and inexpensive supply of petroleum $[1,2]$. In addition, the goals of developing countries - to exploit their natural resources and to supply foodstuffs for the burgeoning populations are based on the assumption of petroleum availability. Most of the world's supply of petroleum comes from the Middle East, Nigeria, Angola, Libya, etc. [3$6]$. Despite this monumental projected importance of modular petroleum plants in remedying unemployment and economic issues, the adverse impact of these modular refineries on their immediate environment and beyond cannot be underemphasized. Therefore, stakeholders should be fully aware of these implications and should take necessary steps while setting up industries so as to minimize the possible adverse effects on environmental resources and quality of life, through careful selection and assessment of identified criteria [7].

The identification of a suitable site for Industrial Development is one of the critical issues in the process of planning, starting, expanding, or changing the location of industrial systems of all kinds [8]. One of the main objectives in industrial site selection is finding the most appropriate site with desired conditions defined by the selected criteria. In a site selection process, the analyst strives to determine the optimum location that would satisfy specified conditions which is a direct determinant of the influence level (weight) of the selected criteria. The most frequently raised problem in MCE is how to establish weights for a set of activities according to importance Mohamed, et al. [9]. Saaty [10] has shown that this weighting of activities in MCE can be dealt with using a theory of measurement in a hierarchical structure. The analytic hierarchy process (AHP) is a comprehensive, logical, and structural framework, which allows improving the understanding of complex decisions by decomposing the problem in a hierarchical structure. The incorporation of all relevant decision criteria and their pairwise comparison allows the decision-maker to determine the trade-offs among objectives. Such multi-criteria decision problems are typical for industrial site selection.

The AHP allows decision-makers to model a complex problem in a hierarchical structure showing the relationship of the goal, objectives (criteria), sub-objectives, and alternatives [9]. Uncertainties and other influencing factors can also be included. It does not only supports decision makers by enabling them to structure complexity and exercise judgment, but also allows them to incorporate both objective and subjective considerations in the decision process [10].

\section{Materials and Methods}

\subsection{Study Area}

The area selected for this study, Edo state is in the South-South geopolitical zones of Nigeria. Edo is a state in southern Nigeria. It was created on 27th August 1991 when the former Bendel State (now Edo and Delta) was separated into these two states. Edo state is located between latitudes $7^{\circ} 18^{\prime} 8.61^{\prime \prime} \mathrm{N}$ to $5^{\circ} 52^{\prime} 48.77^{\prime \prime} \mathrm{N}$ of the equator and longitudes $6^{\circ} 36^{\prime} 59.29^{\prime \prime} \mathrm{E}$ to $5^{\circ} 12^{\prime} 58.38^{\prime \prime} \mathrm{E}$ of the Greenwich meridian, with a surface area of approximately $19,603 \mathrm{~km} 2$. Its capital is Benin City. With a population of 3,218,332 million people (2006 Census). It is bounded in the north and east by Kogi State, in the south by Delta State, and in the west by Ondo State. Economically, Edo state is more of a commercial and agricultural driven state. The majority of its population are either farmers or traders. There are various solid mineral deposits within the state such as; industrial clay, silica, lignite, kaolin, tar sand, decorative rocks, limestone, etc. still waiting to be properly used to their full potential. Edo state also has deposits of crude oil and this makes it one of the petroleum-producing states in Nigeria. Figure 1, is the Map of Nigeria showing the study area (Edo state) and the satellite image of Edo state.

\subsection{Research Instrument}

A total of one hundred (100) experts which consist of Planners, Oil and Gas Engineers, and Geomaticians/Environmentalists within Edo state were proposed via a simple random sampling system. However, since the population is finite, it becomes imperative to apply a statistical model in determining the sample size. Thus, Yamane [11] formula was employed, at an acceptable level of probability of whose confidence level is set at 0.05 as displayed in Equation 1.

Thus;

Where;

$$
n=\frac{N}{1+N(e)^{2}}
$$

$n=$ Sample size

$\mathbf{e}=$ level of significance $(\mathrm{e}=0.05)$

$\mathbf{N}=$ Population size $(\mathrm{N}=100)$

$1=$ Constant

Applying the above formula, population size was computed as follows:

$n=\frac{100}{1+100(0.05) 2}$

$n=\frac{100}{1+100(0.0025)}=\frac{100}{1.25}=80$ 


\subsection{Selection of Criteria}

Based on reviewed pieces of literature and guidelines from relevant authorities, in this case, Department of Petroleum Resources, Nigerian National Petroleum Company, and Environmental Impact Assessment Act (EIA) on the siting of petroleum refining plants, the following fifteen (15) criteria (factors/constraints) were identified and considered in this research. Table 1 shows the criteria (factors/constraints) and the applied codes.

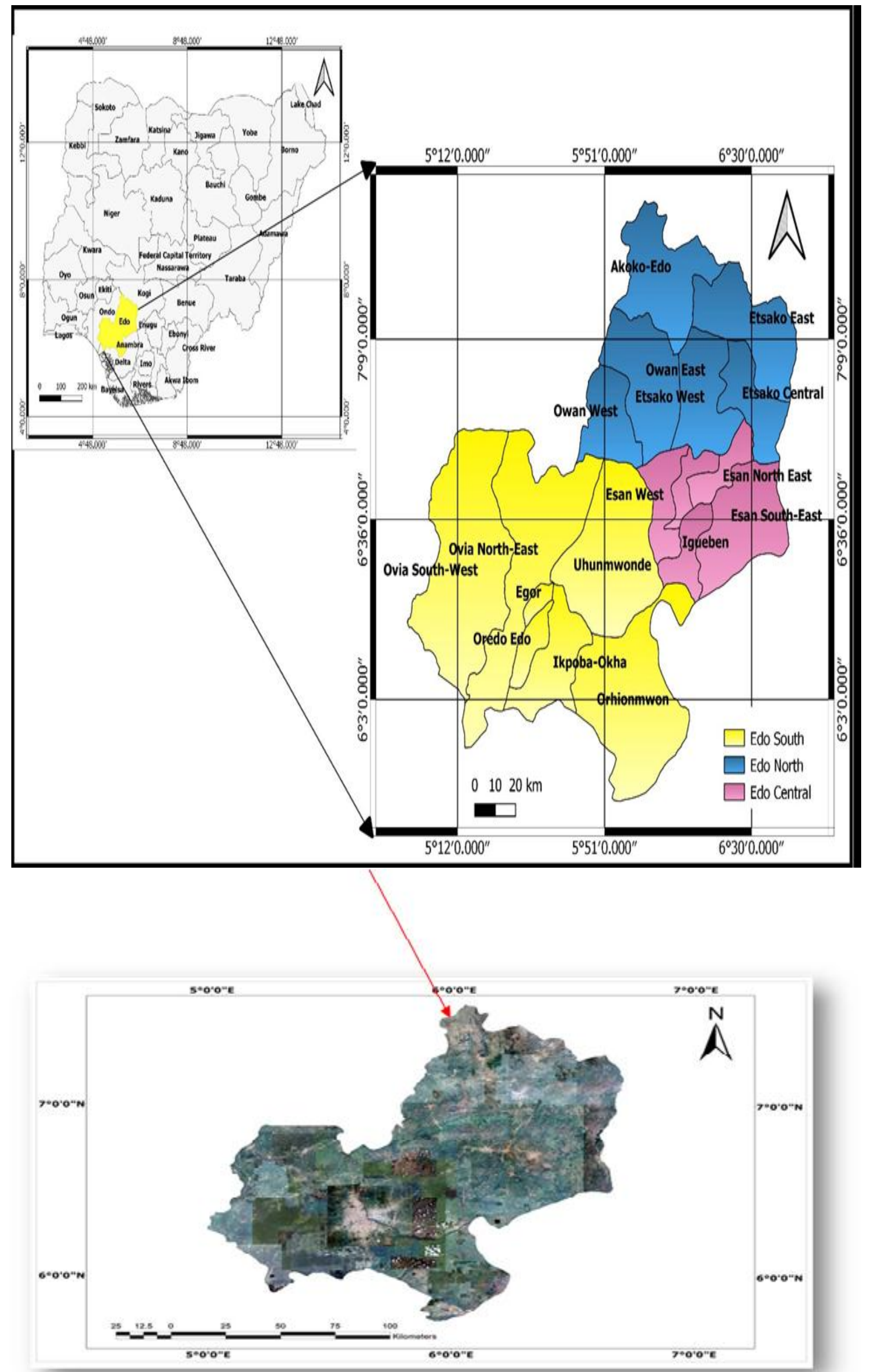

Figure-1. Map of Nigeria showing the study area (Edo state) and the satellite image of Edo State. 


\begin{tabular}{l|l|l|l}
\multicolumn{4}{c}{ Table-1. Criteria (factors / constraints) and Codes Used. } \\
\hline $\mathbf{S} / \mathbf{n}$ & Criterion (Input) & Factors/ Constraints & Code \\
\hline 1 & Water bodies proximity & Factor & MWB \\
\hline 2 & Electricity transmission line proximity & Factor & ETL \\
\hline 3 & Land use / Land cover & Factor & LULC \\
\hline 4 & Topography & Factor & TOPO \\
\hline 5 & Sensitive and protected areas proximity & Constraint & SPA \\
\hline 6 & Critically Polluted areas (refuse dump sites, landfill sites etc.) & Constraint & CPA \\
\hline 7 & Proximity to Existing Industrial areas & Factor & EIA \\
\hline 8 & Transportation network & Factor & MTN \\
\hline 9 & Flood zones & Constraint & FZ \\
\hline 10 & Raw material supply (Crude oil) & Factor & SRM \\
\hline 11 & Wind speed & Factor & WS \\
\hline 12 & Large-scale Mines & Constraint & LSM \\
\hline 13 & Population density & Factor & PD \\
\hline 14 & Proximity to major settlement & Constraint & MS \\
\hline 15 & Ground Water level & Constraint & GWL \\
\hline
\end{tabular}

\subsection{Pairwise Comparisons}

The pairwise comparisons method was developed by Saaty [10] in the context of the Analytical Hierarchy Process (AHP). This method of criteria weight assessment involves pairwise comparisons to create a ratio matrix. As input, it takes the pairwise comparisons of the parameters in numerical form (i.e. on a scale of 1 to 9) and produces their relative weights as output. One (1) on the scale means that the two factors are equally important and 9 means that the one factor is absolutely more important than the other as shown in Table 2 . If a factor is less important than another then this is indicated by reciprocals of the 1 to 9 values (i.e.1/2 to $1 / 9$ ).

Table-2. Preferences made on 1-9 Scale.

\begin{tabular}{|c|c|}
\hline Numeric Rating (Judgment value) & AHP Scale of Importance for comparison pair \\
\hline 9 & Extreme importance \\
\hline 8 & Very strong to extremely \\
\hline 7 & Very strong importance \\
\hline 6 & Strongly to very strong \\
\hline 5 & Strong importance \\
\hline 4 & Moderately to strong \\
\hline 3 & Moderate importance \\
\hline 2 & Equally to moderately \\
\hline 1 & Equal importance \\
\hline
\end{tabular}

Source: Saaty [10].

\subsubsection{Pairwise Comparison Matrix Formation}

The pairwise matrix (Table 3) was formed using the judgment value of comparison as the matrix elements and following the basic formation rules as established by Saaty [10] and Mohamed, et al. [9]. For example, the judgment value of MWB (LHS) against ETL (RHS) is "6", therefore, the matrix element in a cell, second roll, the third column $(2,3)$ is " 6 "; the judgment value of FZ (LHS) against TOPO (RHS) is " 3 " therefore, the matrix element in a cell, tenth roll, fifth column $(10,5)$ is " 3 "; (i.e. $1 / 3)$, etc.

Table-3. Pair-wise comparison matrix of the study.

\begin{tabular}{|c|c|c|c|c|c|c|c|c|c|c|c|c|c|c|c|}
\hline & MWB & ETL & LULC & TOPO & SPA & CPA & EIA & MTN & FZ & SRM & WS & LSM & PD & MS & GWL \\
\hline MWB & 1.00 & 6.00 & 0.25 & 3.00 & 7.00 & 5.00 & 0.25 & 5.00 & 7.00 & 0.33 & 4.00 & 6.00 & 1.00 & 4.00 & 1.00 \\
\hline ETL & 0.17 & 1.00 & 0.11 & 0.33 & 1.00 & 2.00 & 0.11 & 0.50 & 2.00 & 0.11 & 0.33 & 1.00 & 0.17 & 0.50 & 0.17 \\
\hline LULC & 4.00 & 9.00 & 1.00 & 6.00 & 9.00 & 8.00 & 1.00 & 7.00 & 9.00 & 1.00 & 6.00 & 8.00 & 3.00 & 7.00 & 3.00 \\
\hline TOPO & 0.33 & 3.00 & 0.17 & 1.00 & 3.00 & 2.00 & 0.17 & 1.00 & 3.00 & 0.17 & 1.00 & 3.00 & 0.33 & 2.00 & 0.33 \\
\hline SPA & 0.14 & 1.00 & 0.11 & 0.33 & 1.00 & 1.00 & 0.11 & 0.25 & 1.00 & 0.11 & 0.25 & 1.00 & 0.17 & 0.50 & 0.17 \\
\hline $\mathrm{CPA}$ & 0.20 & 0.50 & 0.13 & 0.50 & 1.00 & 1.00 & 0.11 & 0.33 & 1.00 & 0.11 & 0.33 & 1.00 & 0.20 & 0.33 & 0.20 \\
\hline EIA & 4.00 & 9.00 & 1.00 & 6.00 & 9.00 & 9.00 & 1.00 & 6.00 & 9.00 & 1.00 & 6.00 & 9.00 & 4.00 & 6.00 & 4.00 \\
\hline MTN & 0.20 & 2.00 & 0.14 & 1.00 & 4.00 & 3.00 & 0.17 & 1.00 & 3.00 & 0.17 & 1.00 & 3.00 & 0.50 & 1.00 & 0.50 \\
\hline $\mathrm{FZ}$ & 0.14 & 0.50 & 0.11 & 0.33 & 1.00 & 1.00 & 0.11 & 0.33 & 1.00 & 0.11 & 0.25 & 1.00 & 0.20 & 0.33 & 0.20 \\
\hline SRM & 3.00 & 9.00 & 1.00 & 6.00 & 9.00 & 9.00 & 1.00 & 6.00 & 9.00 & 1.00 & 5.00 & 9.00 & 4.00 & 6.00 & 4.00 \\
\hline WS & 0.25 & 3.00 & 0.17 & 1.00 & 4.00 & 3.00 & 0.17 & 1.00 & 4.00 & 0.20 & 1.00 & 4.00 & 0.50 & 1.00 & 1.00 \\
\hline LSM & 0.17 & 1.00 & 0.13 & 0.33 & 1.00 & 1.00 & 0.11 & 0.33 & 1.00 & 0.11 & 0.25 & 1.00 & 0.17 & 0.25 & 0.25 \\
\hline PD & 1.00 & 6.00 & 0.33 & 3.00 & 6.00 & 5.00 & 0.25 & 2.00 & 5.00 & 0.25 & 2.00 & 6.00 & 1.00 & 2.00 & 2.00 \\
\hline MS & 0.25 & 2.00 & 0.14 & 0.50 & 2.00 & 3.00 & 0.17 & 1.00 & 3.00 & 0.17 & 1.00 & 4.00 & 0.50 & 1.00 & 1.00 \\
\hline GWL & 1.00 & 6.00 & 0.33 & 3.00 & 6.00 & 5.00 & 0.25 & 2.00 & 5.00 & 0.25 & 1.00 & 4.00 & 0.50 & 1.00 & 1.00 \\
\hline Total & 15.85 & 59.00 & 5.12 & 32.33 & 64.00 & 58.00 & 4.97 & 33.75 & 63.00 & 5.09 & 29.42 & 61.00 & 16.23 & 32.92 & 18.82 \\
\hline
\end{tabular}

Basic Rule: If the criterion in the column is preferred to the criteria in the row, then, the inverse of the judgment value is given, otherwise, the actual judgment value.

Note: The numbers represent expert judgment values of the importance of one factors in relation to other factors in the suitable siting of a modular refinery.

2.5.Demonstration of Satty's Ranking Scale for Judgment Values

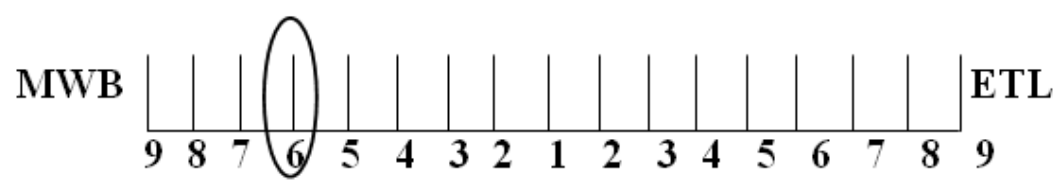


By this judgment value, it means that siting the refinery in close proximity to major water bodies (MWB) is strongly important than its proximity to electricity transmission line (ELT).

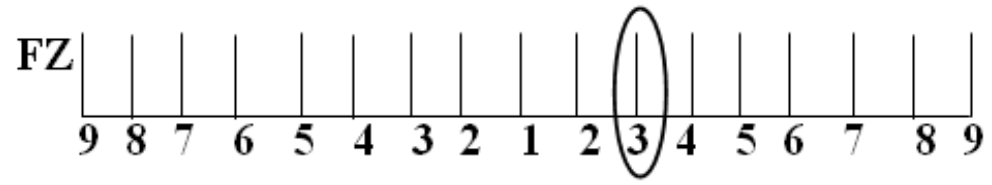

\section{TOPO}

By this judgment value, it means that topography (slope) is moderately important than proximity to flood zone (FZ).

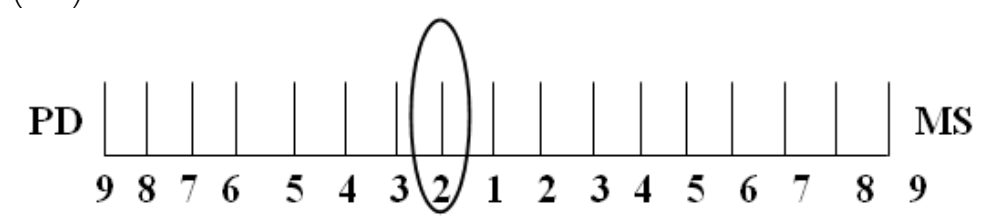

By this judgment value, Population density is slightly more important than Major Settlement.

\subsection{Computation of the Criterion Weights}

This involves the following operations;

(a) Formation of normalized pairwise comparison matrix.

(b) Formation of the prioritization weight matrix.

\subsubsection{Normalized Pairwise Comparison Matrix Formation}

The normalized pairwise comparison matrix was formed from the Pairwise Comparison Matrix in Table 4. Here, the elements of the normalized matrix were formed by dividing the elements of each column by their sum total. For instance, the first element of the first column of the normalized matrix is computed thus; $1 / 15.85=0.06$. Where 1 is the first element of the first column of the pairwise comparison matrix and 15.85 is the sum total of its column.

Table-4. Normalized pairwise comparison matrix.

\begin{tabular}{l|l|l|l|l|l|l|l|l|l|l|l|l|l|l|l}
\hline & MWB & ETL & LULC & TOPO & SPA & CPA & EIA & MTN & FZ & SRM & WS & LSM & PD & MS & GWL \\
\hline MWB & 0.06 & 0.10 & 0.05 & 0.09 & 0.11 & 0.09 & 0.05 & 0.15 & 0.11 & 0.07 & 0.14 & 0.10 & 0.06 & 0.12 & 0.05 \\
\hline ETL & 0.01 & 0.02 & 0.02 & 0.01 & 0.02 & 0.03 & 0.02 & 0.01 & 0.03 & 0.02 & 0.01 & 0.02 & 0.01 & 0.02 & 0.01 \\
\hline LULC & 0.25 & 0.15 & 0.20 & 0.19 & 0.14 & 0.14 & 0.20 & 0.21 & 0.14 & 0.20 & 0.20 & 0.13 & 0.18 & 0.21 & 0.16 \\
\hline TOPO & 0.02 & 0.05 & 0.03 & 0.03 & 0.05 & 0.03 & 0.03 & 0.03 & 0.05 & 0.03 & 0.03 & 0.05 & 0.02 & 0.06 & 0.02 \\
\hline SPA & 0.01 & 0.02 & 0.02 & 0.01 & 0.02 & 0.02 & 0.02 & 0.01 & 0.02 & 0.02 & 0.01 & 0.02 & 0.01 & 0.02 & 0.01 \\
\hline CPA & 0.01 & 0.01 & 0.02 & 0.02 & 0.02 & 0.02 & 0.02 & 0.01 & 0.02 & 0.02 & 0.01 & 0.02 & 0.01 & 0.01 & 0.01 \\
\hline EIA & 0.25 & 0.15 & 0.20 & 0.19 & 0.14 & 0.16 & 0.20 & 0.18 & 0.14 & 0.20 & 0.20 & 0.15 & 0.25 & 0.18 & 0.21 \\
\hline MTN & 0.01 & 0.03 & 0.03 & 0.03 & 0.06 & 0.05 & 0.03 & 0.03 & 0.05 & 0.03 & 0.03 & 0.05 & 0.03 & 0.03 & 0.03 \\
\hline PFZ & 0.01 & 0.01 & 0.02 & 0.01 & 0.02 & 0.02 & 0.02 & 0.01 & 0.02 & 0.02 & 0.01 & 0.02 & 0.01 & 0.01 & 0.01 \\
\hline SRM & 0.19 & 0.15 & 0.20 & 0.19 & 0.14 & 0.16 & 0.20 & 0.18 & 0.14 & 0.20 & 0.17 & 0.15 & 0.25 & 0.18 & 0.21 \\
\hline WS & 0.02 & 0.05 & 0.03 & 0.03 & 0.06 & 0.05 & 0.03 & 0.03 & 0.06 & 0.04 & 0.03 & 0.07 & 0.03 & 0.03 & 0.05 \\
\hline LSM & 0.01 & 0.02 & 0.02 & 0.01 & 0.02 & 0.02 & 0.02 & 0.01 & 0.02 & 0.02 & 0.01 & 0.02 & 0.01 & 0.01 & 0.01 \\
\hline PD & 0.06 & 0.10 & 0.07 & 0.09 & 0.09 & 0.09 & 0.05 & 0.06 & 0.08 & 0.05 & 0.07 & 0.10 & 0.06 & 0.06 & 0.11 \\
\hline PMS & 0.02 & 0.03 & 0.03 & 0.02 & 0.03 & 0.05 & 0.03 & 0.03 & 0.05 & 0.03 & 0.03 & 0.07 & 0.03 & 0.03 & 0.05 \\
\hline GWL & 0.06 & 0.10 & 0.07 & 0.09 & 0.09 & 0.09 & 0.05 & 0.06 & 0.08 & 0.05 & 0.03 & 0.07 & 0.03 & 0.03 & 0.05 \\
\hline Total & 1.00 & 1.00 & 1.00 & 1.00 & 1.00 & 1.00 & 1.00 & 1.00 & 1.00 & 1.00 & 1.00 & 1.00 & 1.00 & 1.00 & 1.00 \\
\hline
\end{tabular}

\subsubsection{Prioritization Weight Matrix Formation}

In computing the element of this matrix, the normalized sum of each row is divided by the total number of its criteria. The obtained values (average) provides the relative weights of the criteria being compared as described in the studies by Permadi [12] and Odell [4]. For instance, the criteria weight of Major Water Bodies (MWB) in this can be obtained thus;

$0.06+0.10+0.05+0.09+0.11+0.09+0.05+0.15+0.11+0.07+0.14+0.10+0.06+0.12+0.05$ (sum of the elements in first row) $=1.35$

Total number of criteria in first row $=15$

Therefore, the weight of Major Water bodies $(\mathrm{MWB})=1.35 / 15=0.09$

Weight of the criteria in percentage $=0.09 \times 100=9 \%$

\subsubsection{Consistency Ratio Check}

In checking the reliability of the respondent's judgments, the consistency ratio $(\mathrm{CR})$ for the judgment values provided by the consulted experts were calculated. According to Saaty [10] if this ratio is found to be less than $10 \%(\mathrm{CR}<0.1)$ then the respondent judgment is consistent if otherwise (i.e. $\mathrm{CR}>0.1)$ then the expert or respondent judgment is not consistent. Calculating the consistency ratio of a judgment involves the following operations: Formation of the weight as factor matrix by introducing the weights of the criteria as the first row of the matrix of comparison. Calculation of the weighted column and weighted sum (consistency vector) by multiplying matrix of comparisons by the vector of priorities (corresponding weights) to get a new column vector.

Calculation of the Average Value of the Consistency Vector by dividing the first component of a new column vector (first element of the weighted sum matrix) by the first component of priorities vector (first element of the weight matrix), the second component of new column vector by the second component of priorities vector, and so on. Calculation of the consistency index by adding up all the elements of the consistency vector $(\lambda \max )$ and applying the mathematical expression $\mathrm{CI}=(\lambda-n) /(n-1)$ where $\mathrm{n}$ is the total number of criteria under consideration (in this case 15) Finally, estimating the consistency ratio via the mathematical expression $\mathrm{CR}=\mathrm{CI} / \mathrm{RI}$ according to Saaty [10] where CI is the consistency index and RI the random index (as given by Saaty [10]). Table 5 below is a 
Matrix whose comparison factors are the considered factors on one side and their respective derived weights on the other. With this matrix, the consistency vector was estimated.

Table-5. Prioritization weight matrix

\begin{tabular}{c|c|c|c|l}
\hline Criteria Code & Row total of the Normalized Matrix & Average & Weight (\%) & Criteria Name \\
\hline MWB & 1.35 & 0.09 & 9.00 & Major WaterBody \\
\hline ETL & 0.26 & 0.02 & 2.00 & Electricity Transmission Line \\
\hline LULC & 2.70 & 0.18 & 18.0 & Landuse/Landcover \\
\hline TOPO & 0.54 & 0.04 & 4.00 & Topography (Slope) \\
\hline SPA & 0.22 & 0.01 & 1.00 & Sensitive/Protected Areas \\
\hline CPA & 0.22 & 0.01 & 1.00 & Critically Polluted Areas \\
\hline EIA & 2.79 & 0.19 & 19.0 & Existing Industrial Areas \\
\hline MTN & 0.53 & 0.04 & 4.00 & Major Transportation Network \\
\hline PFZ & 0.21 & 0.01 & 1.00 & Proximity to Flood Zones \\
\hline SRM & 2.70 & 0.18 & 18.0 & Source of Raw Materials \\
\hline WS & 0.62 & 0.04 & 4.00 & Wind Speed \\
\hline LSM & 0.22 & 0.01 & 1.00 & Large Scale Mines \\
\hline PD & 1.14 & 0.08 & 8.00 & Population Density \\
\hline PMS & 0.53 & 0.04 & 4.00 & Proximity to Major Settlements \\
\hline GWL & 0.95 & 0.06 & 6.00 & Groundwater Level
\end{tabular}

Table-6. The weights as factor matrix.

\begin{tabular}{|c|c|c|c|c|c|c|c|c|c|c|c|c|c|c|c|}
\hline Code & MWB & ETL & LULC & ТОРО & SPA & CPA & EIA & MTN & PFZ & SRM & WS & LSM & PD & PMS & GWL \\
\hline weights & 0.09 & 0.02 & 0.18 & 0.04 & 0.01 & 0.01 & 0.19 & 0.04 & 0.01 & 0.18 & 0.04 & 0.01 & 0.08 & 0.04 & 0.06 \\
\hline MWB & 1.00 & 6.00 & 0.25 & 3.00 & 7.00 & 5.00 & 0.25 & 5.00 & 7.00 & 0.33 & 4.00 & 6.00 & 1.00 & 4.00 & 1.00 \\
\hline ETL & 0.02 & 1.00 & 0.11 & 0.33 & 1.00 & 2.00 & 0.11 & 0.50 & 2.00 & 0.11 & 0.33 & 1.00 & 0.17 & 0.50 & 0.17 \\
\hline LULC & 4.00 & 9.00 & 1.00 & 6.00 & 9.00 & 8.00 & 1.00 & 7.00 & 9.00 & 1.00 & 6.00 & 8.00 & 3.00 & 7.00 & 3.00 \\
\hline TOPO & 0.33 & 3.00 & 0.17 & 1.00 & 3.00 & 2.00 & 0.17 & 1.00 & 3.00 & 0.17 & 1.00 & 3.00 & 0.33 & 2.00 & 0.33 \\
\hline SPA & 0.14 & 1.00 & 0.11 & 0.33 & 1.00 & 1.00 & & 0.25 & 1.00 & 0.11 & 0.25 & 1.00 & 0.17 & 0.50 & 0.17 \\
\hline $\mathrm{CPA}$ & 0.20 & 0.50 & 0.13 & 0.50 & 1.00 & 1.00 & 0.11 & 0.33 & 1.00 & 0.11 & 0.33 & 1.00 & 0.20 & 0.33 & 0.20 \\
\hline EIA & 4.00 & 9.00 & 1.00 & 6.00 & 9.00 & 9.00 & 1.00 & 6.00 & 9.00 & 1.00 & 6.00 & 9.00 & 4.00 & 6.00 & 4.00 \\
\hline MTN & 0.20 & 2.00 & 0.14 & 1.00 & 4.00 & 3.00 & 0.17 & 1.00 & 3.00 & 0.17 & 1.00 & 3.00 & 0.50 & 1.00 & 0.50 \\
\hline PFZ & 0.14 & 0.50 & 0.11 & 0.33 & 1.00 & 1.00 & 0.11 & 0.33 & 1.00 & 0.11 & 0.25 & 1.00 & 0.20 & 0.33 & 0.20 \\
\hline SRM & 3.00 & 9.00 & 1.00 & 6.00 & 9.00 & 9.00 & 1.00 & 6.00 & 9.00 & 1.00 & 5.00 & 9.00 & 4.00 & 6.00 & 4.00 \\
\hline WS & 0.25 & 3.00 & 0.17 & 1.00 & 4.00 & 3.00 & 0.17 & 1.00 & 4.00 & 0.20 & 1.00 & 4.00 & 0.50 & 1.00 & 1.00 \\
\hline LSM & 0.17 & 1.00 & 0.13 & 0.33 & 1.00 & 1.00 & 0.11 & 0.33 & 1.00 & 0.11 & 0.25 & 1.00 & 0.17 & 0.25 & 0.25 \\
\hline $\mathrm{PD}$ & 1.00 & 6.00 & 0.33 & 3.00 & 6.00 & 5.00 & 0.25 & 2.00 & 5.00 & 0.25 & 2.00 & 6.00 & 1.00 & 2.00 & 2.00 \\
\hline PMS & 0.25 & 2.00 & 0.14 & 0.50 & 2.00 & 3.00 & 0.17 & 1.00 & 3.00 & 0.17 & 1.00 & 4.00 & 0.50 & 1.00 & 1.00 \\
\hline GWL & 1.00 & 6.00 & 0.33 & 3.00 & 6.00 & 5.00 & 0.25 & 2.00 & 5.00 & 0.25 & 1.00 & 4.00 & 0.50 & 1.00 & 1.00 \\
\hline TOTAL & 15.85 & 59.00 & 5.12 & 32.33 & 64.00 & 58.00 & 4.97 & 33.75 & 63.00 & 5.09 & 29.42 & 61.00 & 16.23 & 32.92 & 18.82 \\
\hline
\end{tabular}

2.6.4. Calculation of Weighted Column and Weighted Sum (Consistency Vector)

The following steps were observed in calculating the consistency vector:

a. A matrix showing the judgment comparisons and derived weights was started.

b. Using the priorities (weight) as factors for each column as shown in Table 6 above, the values in each column of the comparison matrix were multiplied by their corresponding criterion weight in that column.

E.g. $0.09 \times 1=0.09,0.09 \times 0.02=0.018 ; 0.09 \times 4=0.36 \ldots \ldots \ldots \ldots \ldots .0 .09 \times 1=0.09$

c. Adding up all the values in each row (weighted sum) e.g. for row 1: $(0.09+0.11+0.05+0.11+0.10+0.08+$ $0.05+0.18+0.10+0.06+0.17+0.09+0.08+0.14+0.06)=1.44$. Table 7 shows the obtained Weighted Column and Consistency Sum Matrix. Table 8 shows the result of the consistency vector. This consistency vector is calculated thus: Divide each of the weighted sums by their corresponding weighted value.

Table-7. Obtained weighted column and consistency sum matrix.

\begin{tabular}{|c|c|c|c|c|c|c|c|c|c|c|c|c|c|c|c|}
\hline$\overline{M W B}$ & ETL & LULC & TOPO & SPA & CPA & EIA & MTN & PFZ & SRM & WS & LSM & PD & PMS & GWL & Weightedsum \\
\hline 0.09 & 0.11 & 0.05 & 0.11 & 0.10 & 0.08 & 0.05 & 0.18 & 0.10 & 0.06 & 0.17 & 0.09 & 0.08 & 0.14 & 0.06 & 1.44 \\
\hline 0.01 & 0.02 & 0.02 & 0.01 & 0.01 & 0.03 & 0.02 & 0.02 & 0.03 & 0.02 & 0.01 & 0.01 & 0.01 & 0.02 & 0.01 & 0.27 \\
\hline 0.36 & 0.16 & 0.18 & 0.22 & 0.13 & 0.12 & 0.19 & 0.25 & 0.13 & 0.18 & 0.25 & 0.12 & 0.23 & 0.25 & 0.19 & 2.94 \\
\hline 0.03 & 0.05 & 0.03 & 0.04 & 0.04 & 0.03 & 0.03 & 0.04 & 0.04 & 0.03 & 0.04 & 0.04 & 0.03 & 0.07 & 0.02 & 0.56 \\
\hline 0.01 & 0.02 & 0.02 & 0.01 & 0.01 & 0.02 & 0.02 & 0.01 & 0.01 & 0.02 & 0.01 & 0.01 & 0.01 & 0.02 & 0.01 & 0.22 \\
\hline 0.02 & 0.01 & 0.02 & 0.02 & 0.01 & 0.02 & 0.02 & 0.01 & 0.01 & 0.02 & 0.01 & 0.01 & 0.02 & 0.01 & 0.01 & 0.23 \\
\hline 0.01 & 0.01 & 0.02 & 0.01 & 0.01 & 0.02 & 0.02 & 0.01 & 0.01 & 0.02 & 0.01 & 0.01 & 0.02 & 0.01 & 0.01 & 0.21 \\
\hline 0.27 & 0.16 & 0.18 & 0.22 & 0.13 & 0.14 & 0.19 & 0.21 & 0.13 & 0.18 & 0.21 & 0.13 & 0.30 & 0.21 & 0.25 & 2.91 \\
\hline 0.02 & 0.05 & 0.03 & 0.04 & 0.06 & 0.05 & 0.03 & 0.04 & 0.06 & 0.04 & 0.04 & 0.06 & 0.04 & 0.04 & 0.06 & 0.64 \\
\hline 0.01 & 0.02 & 0.02 & 0.01 & 0.01 & 0.02 & 0.02 & 0.01 & 0.01 & 0.02 & 0.01 & 0.01 & 0.01 & 0.01 & 0.02 & 0.23 \\
\hline 0.09 & 0.10 & 0.06 & 0.11 & 0.09 & 0.08 & 0.05 & 0.07 & 0.07 & 0.04 & 0.08 & 0.09 & 0.08 & 0.07 & 0.13 & 1.20 \\
\hline
\end{tabular}




\begin{tabular}{c|c}
\multicolumn{2}{c}{ Table-8. The consistency vector. } \\
\hline Weighted sum & Consistency vector \\
\hline $1.44 / 0.089$ & 16.18 \\
\hline $0.27 / 0.018$ & 15.00 \\
\hline $2.94 / 0.180$ & 16.33 \\
\hline $0.56 / 0.036$ & 15.55 \\
\hline $0.22 / 0.015$ & 14.62 \\
\hline $0.23 / 0.015$ & 15.33 \\
\hline $3.04 / 0.186$ & 16.34 \\
\hline $0.55 / 0.036$ & 15.28 \\
\hline $0.21 / 0.014$ & 15.00 \\
\hline $2.91 / 0.179$ & 16.26 \\
\hline $0.64 / 0.042$ & 15.24 \\
\hline $0.23 / 0.015$ & 15.33 \\
\hline $1.20 / 0.076$ & 15.97 \\
\hline $0.55 / 0.036$ & 15.28 \\
\hline $1.00 / 0.064$ & 15.63 \\
\hline
\end{tabular}

\subsubsection{Calculation of the Consistency Index}

Where $n=$ total number of considered factors which in this case is 15 , and $(\lambda \max )$ the summation of the elements of the consistency vector, CI (consistency index) can be calculated by the formula; CI $=\{(\lambda-n) /(n-1)\}$ [10]

Therefore, $\lambda_{\max }=(16.18+15.00+16.33+15.55+14.67+15.33+16.34+15.28+15.00+16.26+15.24+15.33$ $+15.79+15.28+15.63) / 15=(233.205 / 15)=15.547$

$\mathrm{CI}=(\lambda-\mathrm{n}) /(\mathrm{n}-1)$

$\mathrm{CI}=(15.547-15) /(15-1)=0.0366$.

In calculating the constituency value, which is a ratio of consistency index to the random index, the mathematical expression; $\mathrm{CR}=\mathrm{CI} / \mathrm{RI}$ according to Saaty [10] was used. Random index (RI) is the inconsistency index of a randomly generated pair-wise comparison matrix of order 1 to 15 obtained by approximating random indices. See Table 9.

\begin{tabular}{|c|c|c|c|c|c|c|c|c|c|c|c|c|c|c|c|c|}
\hline $\mathbf{n}$ & 1 & 2 & 3 & 4 & 5 & 6 & 7 & 8 & 9 & 1 & 11 & 12 & 13 & 14 & 15 & 16 \\
\hline $\mathrm{RI}$ & $\mathrm{O}$ & 0.00 & 0.52 & 0.89 & 1.11 & 1.25 & 1.35 & 1.40 & 1.45 & 1.49 & 1.52 & 1.54 & 1.56 & 1.58 & 1.59 & 1.73 \\
\hline
\end{tabular}

Where $\mathrm{n}=$ order of matrix

When the order of a comparison matrix is $\mathrm{n}>15$, the average values of the random index CI may be roughly calculated using Podvezko [13] formula as displayed in Equation 2:

$$
C l=\frac{1.98(n-2)}{n}
$$

Where $\mathrm{n}=$ number of criteria under consideration.

Consequently, the consistency ratio, in this case is $\mathrm{CR}=\mathrm{CI} / \mathrm{RI}$.

$\mathrm{CR}$ in this case is; $0.0366 / 1.59=0.023$

\section{Result and Analysis}

Table 5 shows the Computed Average Criteria Weight for Consistent Respondents which revealed the influence level of the individual criteria considered for this study. The result from the calculated environmental criteria weights show that proximity of Petroleum refinery to existing industrial areas; source of crude oil and Landuse/Landcover to have the highest influence value, followed by proximity to Water Body; Population Density; Groundwater Level; Major Settlement; Wind Speed; Transportation Network, Topography, while Sensitive/Protected Areas, Critically Polluted areas, and Flood zones with the least influence value. The result of this AHP - based weight assessment would play a key role in any decision-making process involving the siting of a petroleum refining plant. It is anticipated that the results of this assessment can be used generally by Planners, Investors, Environmental Managers, and Oil and Gas experts as a general guide in the prioritization of criteria weights based on the influence of one criterion over the other in the suitability siting of petroleum refining plant. The result of this AHP - based weight assessment will play a key role in any decision-making process involving the siting of a petroleum refining plant. It is anticipated that the results of this assessment can be used generally by Planners, Investors, Environmental Managers and Oil and Gas experts as a general guide in the prioritization of criteria weights based on the influence of one criterion over the other in the suitability siting of petroleum refining plant. The findings agreed with the several studies $[11,13]$.

As a check on the reliability of respondents' judgments, the Consistency Ratio $(\mathrm{CR})$ for the judgment values was calculated. This Consistency Ratio value was found to be 0.023, which is less than 0.1. According to Saaty [10] if this ratio is found to be less than $10 \%(\mathrm{CR}<0.1)$ then the respondent judgment is consistent, if otherwise (i.e. $\mathrm{CR}>0.1)$ then the judgment is not consistent. By the result of this study, it means that there is a reasonable level of consistency in the comparison of the criteria by the respondent of this very outcome and that the computed weights are within the acceptable limit. If the reverse was the case $(\mathrm{CR}>0.1)$ it means that the weights obtained are inconsistent and the judgment values need to be checked for logical correctness. $75 \%$ (60) of the total number of respondents were consistent in their judgment and the remaining 25\% (14) were inconsistent. These inconsistencies in judgment by the responders may be a lack of logical knowledge of the Pairwise Comparison. 


\section{Conclusion}

Investors are constantly faced with tough decisions on the location of facilities that will yield the highest returns on low environmental impact. To optimize the benefits and constraints of particular land uses in a certain area, a planner needs to have a good knowledge of the influence of one criterion over the other. The Analytic Hierarchy Process (AHP) has been proved by literature and existing projects to produce reliable and consistent results since it provides an alternative for a check and the fact that it can deal with inconsistent judgments and provides a measure of the inconsistency of the judgment makes the methodology a better solution that can help deal with the complex problems of a suitable site a selection like the one of this research (modular petroleum refining plant siting), which involves the consideration of multi-criteria/alternatives simultaneously. It is anticipated that the results of this assessment can be used generally by Planners, Investors, Environmental Managers, and Oil and Gas experts as a general guide during criteria weighting and prioritization based on the influence of one criterion over the other in the suitability siting of petroleum refining plant.

\section{References}

[1] J. F. K. Akinbami, "An analysis of the demand and supply of electricity and the greenhouse gases emissions of the Nigerian electrical power industry," A Ph.D. Thesis, Technology Planning and Development Unit (TPDU), Obafemi Awolowo University, Ile-Ife, Nigeria, 2003.

C. J. Campbell, The essence of oil and gas depletion. Brentwood, New York: Multi-Science Publishing Co, 2003.

R. Heinberg, The party's over: Oil, war and the fate of industrialized societies. British Columbia: New Society Publishing, 2003.

P. R. Odell, Why carbon fuels will dominate the 21 st century's global energy economy. Essex, UK: Multi-Science Publishing Company Ltd, 2004.

[5] A. Milbrandt and R. P. Overend, "The future of liquid biofuels for APEC economies," Report Prepared for APEC Energy Working Group2008.

[6] U.S. Energy Information Administration (EIA), International energy outlook (IEO): Highlights. Washington DC: US Department of Energy, 2010.

[7] U.S. Energy Information Administration (EIA), International energy statistcis. Washington DC: US Department of Energy, 2014.

[8] P. Negi and K. Jain, "Spatial multi-criteria analysis for siting groundwater polluting industries," Journal of Environmental Informatics, vol. 12, pp. 54-63, 2008.

[9] A. Mohamed, B. Shattri, B. Nordin, and S. Rashid, "GIS based multicriteria approaches to housing site suitability assessment. TS 72 - GIS spplications - planning," presented at the Shaping the Change, XXIII FIG Congress, Munich, Germany, October 8-13, 2006.

[10] T. L. Saaty, The analytic hierarchy process. New York: McGraw-Hill, 1980.

[11] T. Yamane, Statistics: An introductory analysis, 2nd ed. New York: Harper and Row, 1967.

[12] Permadi, "Multi-criteria land suitability evaluation for selected fruit crops in Hilly Region of Central Vietnam," PhD Dissertation Submitted to Humboldt University of Berlin, Germany, 1992.

[13] V. Podvezko, "Complex evaluation of complex quantities," Business: Theory and Practice, vol. 9, pp. 160-168, 2008. 